\title{
Multimegawatt MPD Thruster Design Considerations
}

Roger M. Myers and James E. Parkes

Sverdrup Technology, Inc.

Lewis Research Center Group

Brook Park, Ohio

and

Maris A. Mantenieks

National Aeronautics and Space Administration

Lewis Research Center

Cleveland, Ohio

Prepared for the

Ninth Symposium on Space Nuclear Power Systems

sponsored by the University of New Mexico

Albuquerque, New Mexico, January 12-16, 1992 


\title{
MULTIMEGAWATT MPD THRUSTER DESIGN CONSIDERATIONS
}

\author{
Roger M. Myers and James E. Parkes \\ Sverdrup Technology, Inc. \\ Lewis Research Center Group \\ Brook Park, Ohio 44142
}

\author{
Maris A. Mantenieks \\ National Aeronautics and Space Administration \\ Lewis Research Center \\ Cleveland, Ohio 44135
}

\begin{abstract}
Performance and lifetime requirements for multimegawatt magnetoplasmadynamic (MPD) thrusters were used to establish a baseline $2.5 \mathrm{MW}$ thruster design. The chamber surface power deposition resulting from current conduction, plasma and surface radiation, and conduction from the hot plasma was then evaluated to establish the feasibility of thruster operation. It was determined that state-of-art lithium heat pipes were adequate to cool the anode electrode, and that the liquid hydrogen propellant could be used to cool the applied-field magnet, cathode, and backplate. Unresolved issues having an impact on thruster design are discussed to help focus future research.
\end{abstract}

\section{Introduction}

Magnetoplasmadynamic (MPD) thrusters are currently being considered for application to primary propulsion systems on scientific and piloted interplanetary missions. The high specific impulse offered by MPD thrusters, between 3000 and 7000 seconds, can reduce launch mass requirements by over a factor of two compared to chemical/aerobraked systems if the power-to-thrust conversion efficiency is over $50 \%$. To satisfy the total impulse requirements for these missions, the thruster system must process between 0.5 and $10 \mathrm{MW}$ of power while lasting over 10,000 hours (Hack 1991, Gilland 1990 and 1991). The purpose of this work is to establish the feasibility of building a steady-state, multimegawatt MPD thruster using current technology and to propose a baseline design which can be expected to yield the required levels of performance and lifetime.

MPD thrusters processing over $0.5 \mathrm{MW}$ of input power have been operated continuously for several hours (Wegmann et al. 1990), and other designs have been pulsed at powers between 5 and $20 \mathrm{MW}$ to study performance scaling (Gilland et al. 1987, Schoenberg et al. 1991). While specific impulses meeting performance requirements have been demonstrated with several thruster configurations (Sovey and Mantenieks 1988) the thruster efficiencies are still substantially below those required for missions of interest. However, substantial data exist indicating this problem can be overcome (Myers et al. 1991a). MPD thruster research between 1970 and 1987 focussed on self-field accelerators, in which the electromagnetic body forces result from the interaction of the discharge current and the self-induced azimuthal magnetic field. Recent work (Myers 1991) has shown that improved performance results from applying an external magnetic field, which results in additional propellant acceleration due to the interaction of the discharge current with the axial and radial magnetic field components. The voltage and thrust of these engines have been shown to increase monotonically with applied-field strength at constant discharge current, indicating a lower discharge current requirement than would be necessary in a self-field accelerator. This not only reduces the cathode current density requirements, but also will increase the propulsion system efficiency via reduced power processor and transmission line losses. At the system level, preliminary designs for both quasi-steady (King and Rudolph 1982, Rudolph and Ogg 1985) and steady-state (Coomes et al. 1986, Gilland et al. 1990) MPD thruster systems have been presented. However, none of these considered in detail the implications of the thermal loading and materials issues confronting long term thruster operation, and all but one considered only self-field MPD thrusters. The purpose of this work is to incorporate recent experimental results and model predictions into a multimegawatt steady-state thruster design, in an attempt to demonstrate the feasibility of long life thrusters operating at high power. In addition, by presenting a preliminary thruster design we focus attention on unresolved issues requiring further research. While large uncertainties remain in the design of operational multimegawatt MPD thrusters, the potential advantages of using these devices, including simplicity, robustness, and relative ease of testing (Sovey et al. 1991), indicate that an assessment of the issues controlling design of operational thrusters is needed.

In this report the impact of applied-field thruster geometry on performance and life is first discussed in order to establish the overall design of a $2.5 \mathrm{MW}$ thruster and illustrate the uncertainties in the geometry. 
The baseline design is then used with the plasma properties and known electrode and insulator phenomena to establish surface heat loads and potential lifetime limiters. Finally, a summary of the study results and unresolved issues is presented.

\section{Thruster Performance Scallng}

Applied-field MPD thruster data have been recently obtained at power levels between 0.05 and $0.22 \mathrm{MW}$, and included direct measurements of thruster performance, calorimetric studies of electrode power deposition, and a preliminary characterization of the thruster plasma characteristics (Myers 1991, Myers et al. 1991, Mantenieks and Myers 1991, Gallimore et al. 1991). The laboratory MPD thrusters, represented schematically in Figure 1, consisted of a central, $2 \% \mathrm{ThO}_{2}$ tungsten, cathode with a coaxial water-cooled copper anode. Propellant was injected through the insulating backplate at the rear of the chamber. Measurements were made over a wide range of thruster propellant flow rates, discharge currents, and applied magnetic field strengths with both argon and hydrogen propellants. The performance measurements clearly showed that, for the operating conditions studied, the thrust scaled as

$$
T \propto \frac{R_{a}^{2}}{k_{1} L_{c} R_{c}} B+k_{2} f\left(L_{a}\right)
$$

where $R_{a}$ and $R_{c}$ are the anode and cathode radii, $L_{a}$ and $L_{c}$ are the anode and cathode lengths, $B$ is the magnetic field strength, and $k_{1}$ and $k_{2}$ are constants. The second term indicates that while the anode length influenced the magnitude of the thrust, it did not affect the rate at which the thrust increased with magnetic field strength. The thruster discharge voltage scaled as

$$
v \propto \frac{R_{a}^{2}}{k_{3} R_{c}} B+k_{4} f\left(L_{a}\right)
$$

where $\mathrm{k}_{3}$ and $\mathrm{k}_{4}$ are constants and the other symbols are defined above. The data used to establish these scaling relationships were also used to study the efficiency behavior. For the operating conditions examined, the rate of efficiency increase with magnetic field strength increased quadratically with anode radius. However, for the operating conditions studied the absolute magnitude of the efficiency decreased with increasing anode radius. This result is illustrated in Figure 2, which shows thruster efficiency as a function of applied magnetic field strength for four different anode radii. The field strengths were limited by the capabilities of the anode cooling system. Presuming the trends remain constant, for applied-field strengths greater than $0.25 \mathrm{~T}$ the efficiency of the $5.1 \mathrm{~cm}$ radius thruster should approach the $50 \%$ required.

Calorimetric studies of electrode power deposition showed that between 50 and $80 \%$ of the input power was deposited into the anode for the selected operating conditions (Myers 1991). While the total power deposited into the anode increased quadratically with anode radius and linearly with applied-field strength, the fraction of the input power deposited into the anode decreased with both increasing anode radius and appliedfield strength. This effect was due to the more rapid increase in thruster power than anode power. Typical results are shown in Figure 3, where the anode power fraction is plotted as a function of applied-field strength for the same four anode radii as used in Figure 2. The anode power measurements indicated that the dominant mechanism of anode power deposition was current conduction across a $10-40 \mathrm{~V}$ anode fall voltage. Evaluation of the thruster plasma properties using electrostatic probes showed that the electrons in the anode fall region were magnetized, with electron Hall parameters ranging from $10-500$. For these conditions electron transport into the anode was severely restricted, leading directly to the high anode fall voltages and associated high anode power deposition. These results suggest that the anode power fraction can be reduced via appropriate tailoring of the propellant injection and anode and applied-magnetic field shapes. Shaping the anode/applied-field such that the magnetic field lines cross its surface should reduce the importance of cross-field transport and thus reduce the dependence of the anode power on the applied field strength.

These results have several implications. First, the measured performance increase with applied-field strength indicate that the solenoidal coil should have the capability of producing a field strength between 0.25 and $0.5 \mathrm{~T}$. A value of $0.5 \mathrm{~T}$ was selected to illustrate the feasiblity of applied-field thrusters. As discussed below, heat flux considerations dictate a minimum magnet radius of approximately $20 \mathrm{~cm}$ due to the requirement for multiple heat shields. A numerical code written by LaPointe (1989) was used to design the required number of turns and current for the magnet to produce a field of $0.5 \mathrm{~T}$. A magnet radius of 20 $\mathrm{cm}$ requires 60 tums of $\mathrm{I} \mathrm{cm}$ square conductor at a current of $2300 \mathrm{~A}$ to produce the required field strength. This increases to $4800 \mathrm{~A}$ if the coil radius is increased to $40 \mathrm{~cm}$. Second, the anode radius and length will be approximately 15 and $30 \mathrm{~cm}$, respectively, and it will most likely be a straight cylinder or have a 
converging-diverging geometry to minimize anode losses. The anode size is determined not only by performance requirements, but also by the need to keep the deposited power density below limits set by the heat removal techniques. Third, the cathode should be as short and have as small a radius as possible, though these parameters will be strongly dependent on the lifetime requirements.

\section{Lifetime Considerations}

The system lifetime required for most missions being considered is 10,000 hours. Achieving this lifetime using several thrusters with short lifetimes significantly increases the system complexity. The approach adopted in this work is to maxinize the probability of success with a single thruster.

The principal life limiter in MPD thrusters is cathode erosion. Recent work has identified evaporation and oxidation as the major erosion mechanisms, with the latter playing a significant role only if the net evaporation rate is reduced to less than $30 \mathrm{ng} / \mathrm{C}$ (Myers et al. 1988, Polk et al. 1990, Myers et al. 199 la). These experimental results also show that backscattering of evaporated cathode material plays a dominant role in establishing the net mass loss rate. For certain thruster geometries with high pressure chambers, erosion rates as low as $2-4 \mathrm{ng} / \mathrm{C}$ can be achieved with high purity propellant (Auweter-Kurtz, 1990). Such values may satisfy the mission lifetime requirements.

The exponential dependence of evaporation rate on surface temperature indicates that the best method of reducing the cathode erosion rate is to reduce its operating temperature. For a thernionic emitter, the surface temperature is approximately linearly dependent on work function, and only varies logarithmically with current density. Thus, the best way to minimize the operating temperature is to minimize the cathode work function. A promising material for this purpose is barium-calcium-aluminate impregnated tungsten, which is currently used in ion thruster hollow cathodes. The operating temperature for these cathodes in ion thrusters is approximately $1400 \mathrm{~K}$ at emission currents of $10-20 \mathrm{~A}$. The low temperature is required to ensure that the barium evaporative loss rate does not exceed the barium diffusion rate to the surface. The hollow cathode enclosure raises the surface pressure on the emitting surface, which enhances backscattering and increases the residence time of the low work function material. Recent testing with hollow cathodes in MPD thrusters (Mantenieks and Myers 1991) indicates that hollow cathodes can be built to operate in the 2000 A current range. While not conclusive, these results also suggest it will be possible to successfully build low work function cathodes for MPD thrusters, and that both rod-shaped and hollow cathode geometries can be successfully used without significantly compromising thruster perfornance.

The impact of sputtering on anode and cathode material loss rates was evaluated by estimating the sputtering threshold energies for hydrogen using the method of Bohdansky (1980). The resulting threshold energies were 406 and $130 \mathrm{eV}$ for tungsten and molybdenum, respectively. It is clear that little or no sputtering will occur on these surfaces with the $13 \mathrm{eV}$ proton energy corresponding to a specific impulse of 5000 seconds.

\subsection{MW Thruster Design}

The proposed $2.5 \mathrm{MW}$ thruster, designed to operate at a discharge voltage of $250 \mathrm{~V}$ and a current of $10,000 \mathrm{~A}$, is shown in Figure 4 . It consists of a $15 \mathrm{~cm}$ radius, $30 \mathrm{~cm}$ long, cylindrical molybdenum anode and a $5 \mathrm{~cm}$ diameter, $10 \mathrm{~cm}$ long, rod-shaped barium-calcium-aluminate impregnated porous tungsten cathode. Propellant is injected into the chamber through small holes in the boron nitride backplate. While a cylindrical anode is shown, use of a converging or a converging-diverging anode would not significantly change the thermal analysis issues discussed below. A hollow cathode was not chosen due to the uncertainties in their operation at high currents, though again the design could easily be modified to accommodate this change. A large radius cathode was selected to ensure that the impregnated cathode current densities would be below $20 \mathrm{~A} / \mathrm{cm}^{2}$ to ensure adequate lifetime (Schroff 1981). To satisfy this requirement the cathode surface will have to be textured (grooved or pitted) to provide for a factor of four increase in surface area.

Fifty $1 \mathrm{~cm}$ diameter lithium heat pipes are used to remove heat deposited into the anode and transport it to a pyrolitic graphite radiator. The lithium heat pipes, operating at a temperature of $1400 \mathrm{~K}$, are capable of removing $400 \mathrm{~kW}$ from the anode while remaining over an order-of-magnitude below the sonic heat transfer limit (Dunn and Reay 1982). Lifetests reported by Dunn (1982) indicate that with a TZM alloy wall, 
lithium heat pipes will last over 9000 hours. The heat fluxes that must be accommodated by the heat pipes and MPD thruster chamber surfaces are discussed below.

\section{Thruster}

\section{Heat Flux Estimation}

Heat loads to MPD thruster surfaces arise from current conduction across plasma/electrode interfaces, the presence of the $1-2 \mathrm{eV}$, high velocity plasma, and radiative exchange between the inner chamber surfaces. By far the largest heat load is to the anode, for which the power deposition can be estimated from (Gallimore et al, 1991)

$$
P_{\mathrm{an}}=\mathrm{J}\left(\mathrm{V}_{\mathrm{a}}+\frac{5 \mathrm{kT}_{\mathrm{e}}}{2 \mathrm{e}}+\Phi\right)+\mathrm{P}_{\mathrm{rad}}+\mathrm{P}_{\text {flow }}
$$

where the first term, in brackets, represents the power deposited by the current carrying electrons; the second represents the power radiated from the cathode and the plasma; and the third is the plasma flow energy transported to the anode. In this equation, $J$ is the discharge current, $V_{a}$ is the anode fall voltage, $T_{e}$ is the electron temperature, $k$ is Boltzmann's constant, $e$ is the electron charge, and $\Phi$ is the electrode work function. Previous work (Myers 1991, Gallimore et al. 1991) has shown that the first term is the dominant power loss mechanism, and that the anode fall voltage is the largest source of electron energy. The magnitude of the first term was estimated assuming an anode fall voltage of $15 \mathrm{~V}$, an electron temperature of $1.5 \mathrm{eV}$, and an anode work function of $4.5 \mathrm{~V}$. While the latter two values are easily justifiable, the anode fall voltage is a factor of $2-3$ lower than that estimated from calorimetric measurements of low power, high specific impulse thrusters (Myers 1991). However, the data indicate that the large anode fall may be greatly reduced by shaping the anode and magnetic field so as to reduce the requirement for cross-field current conduction. If this reduction is not achieved, it is doubtful whether MPD thrusters will be viable candidates for propulsion applications. For the assumed values, the first term in eqn. 1 yields a power deposition of $0.23 \mathrm{MW}$ for a 10,000 A discharge current, corresponding to $0.82 \mathrm{MW} / \mathrm{m}^{2}$ for the proposed geometry. This heat flux is within the capabilities of the lithium heat pipes. The anode power drops to $0.21 \mathrm{MW}$ if the anode naterial is barium impregnated porous tungsten with a work function of $2.6 \mathrm{eV}$. This result illustrates the premium placed on reduction of the anode fall voltage.

It will be shown below that the other terms in the anode power balance are very small, so that the lithium heat pipe/pyrolytic graphite radiator can be sized using the $0.23 \mathrm{MW}$ found above. Assuming an emissivity of 0.9 and a temperature of $1400 \mathrm{~K}$ for the radiator surface, the outer diameter of the radiator must be $1.2 \mathrm{~m}$.

The effect of internal chamber surface radiation was estimated by calculating the cathode - anode, anode anode, cathode - backplate, and anode - backplate view factors and assuming grey body radiation at a uniform surface temperature. The view factors were estimated using relations for straight, finite length, cylinders (Siegel and Howell 1972). The electrode surface temperatures were set to $1400 \mathrm{~K}$ based on use of lithium heat pipes for the anode and a barium-calcium-aluminate impregnated tungsten cathode. The electrode emissivities were set to 0.4 , and the insulating backplate emissivity was set to 0.1 , typical values for the materials used. Three equations for the net heat fluxes to the surfaces, in terms of the emitted power and the radiosity, were developed and solved simultaneously for the heat fluxes. The backplate temperature was left as a free-parameter as there was no independent method of establishing its temperature. The resulting equations are:

$$
\begin{aligned}
& Q_{B}=3.8 \times 10^{-10} \mathrm{~T}_{B}{ }^{4}-1490, \mathrm{~W} \\
& Q_{C}=-5.6 \times 10^{-1} \mathrm{~T}_{\mathrm{B}^{4}}+221, \mathrm{~W} \\
& \mathrm{Q}_{\mathrm{A}}=-3.3 \times 10^{-10} \mathrm{~T}_{\mathrm{B}}{ }^{4}+1218, \mathrm{~W}
\end{aligned}
$$

where $Q_{A}, Q_{B}$, and $Q_{C}$ are, respectively, the heat fluxes from the anode, backplate, and cathode (a negative value indicating net heat input), and $T_{B}$ is the backplate temperature. The equations do not depend directly on thruster power level, but rather on geonetry, materials, and surface temperatures. The largest radiated heat flux is to the backplate, reaching almost $1 \mathrm{~kW}$ if its surface temperature is $1100 \mathrm{~K}$. Heat fluxes to the cathode and anode are negligibly small if their temperatures are equal. An important issue not yet addressed in detail is the emissivity changes which will occur over the lifetime of the thruster. In current testing of MPD thrusters the backplate is typically coated with contaninants within the first few minutes of operation. 
The contribution of the plasma to the chamber surface heat flux consists of thermal particle flux, free free, free-bound, and line radiation. While the scaling of the plasma density and temperature are poorly understood, order-of-magnitude estimates can be obtained from simple kinetic theory and plume plasma measurements in applied-field thrusters (Myers et al. 199 lb).

The thermal loads on the cathode and backplate resulting from particle flux to the surfaces were estimated from simple kinetic theory. The particle heat flux to the anode was included in the first term of eqn 3. Assuming equal electron and ion temperatures, the surface power fluxes are given by

$$
P_{s}=\frac{N c}{4} E_{p}
$$

for an attracting surface potential, or

$$
P_{s}=\frac{N c}{4} \exp \left(-\frac{V_{s}}{k T_{e}}\right) E_{p}
$$

for a retarding potential. In these equations, $T$ is the particle temperature, $c$ is the mean particle thermal speed, $\mathrm{N}$ the particle density, $\mathrm{V}_{\mathrm{S}}$ the difference between the plasma and surface potential, and $\mathrm{E}_{\mathrm{p}}$ the energy deposited into the surface by the incoming particle. The ion energy term must include the recombination energy (13.6 eV/atom for hydrogen) if the surface is conducting. Note that these relations do not include thermalization in the boundary layer, so that the ion energy to the cathode includes the kinetic energy of the flow and that acquired across the cathode fall, recombination, and thermal energies. Assuming a leV temperature, setting $V_{S}$ to $-5 \mathrm{~V}$ for the cathode, and utilizing the floating potential for the insulating backplate, the electron and ion thermal fluxes were estimated to be approximately $2.21 \mathrm{~kW}$ onto the cathode and $8.9 \mathrm{~kW}$ onto the backplate for the chosen geometry. If the ions recombine on the backplate this value increases to $17 \mathrm{~kW}$. In addition, removing the cathode from the high speed flow will reduce the ion heat flux to its surface to $1.3 \mathrm{~kW}$.

Free-free, free-bound, and line radiation contributions were estimated following the formalisms described in Lochte-Holtgraven (1968) and Griem (1964). Assuming a Maxwellian distribution function for the particles, which may be inappropriate in a highly magnetized plasma, the power emitted via free-free radiation is:

and the free - bound radiation is:

$$
P_{f f}=1.13 \times 10^{-41} \Omega V T_{e}^{1 / 2} N_{e} N_{i}
$$

$$
P_{f b}=5.4 \times 10^{-52} T_{e}^{-1 / 2} N_{e} N_{j} \Omega v\left(\frac{E_{H}}{h n^{2}}+\frac{k T_{e}}{h}\left(\exp \left(-\frac{E_{H}}{k T_{e} n^{2}}\right)-1\right)\right)
$$

where $T_{e}$ is the electron temperature, $\Omega$ is the solid angle, $n$ is the lowest quantum level into which recombination occurs, $\mathrm{V}$ is the emitting volume, and $\mathrm{N}_{\mathrm{e}}$ and $\mathrm{N}_{\mathrm{i}}$ are the electron and ion number densities. Line radiation was estimated by multiplying the resonance transition energy by the electron excitation rate, and assuming the plasma is optically thin to obtain a worst-case value. The result was:

$$
P_{1}=2.1 \times 10^{-32} \mathrm{~N}_{\mathrm{e}} \mathrm{N}_{\mathrm{a}} \Omega V \exp \left(-\frac{\mathrm{E}_{2}}{\mathrm{kT}_{\mathrm{e}}}\right)
$$

where $E_{2}$ is the resonance line energy, $\mathrm{N}_{\mathrm{a}}$ the neutral atom density, and other terms are as defined above. The contributions of these terms with an electron temperature and density of $1.5 \mathrm{eV}$ and $1 \times 10^{14} \mathrm{~cm}^{-3}$, respectively, and an ionization fraction of $50 \%$ are $1.9,1.9$ and $9.0 \mathrm{~kW}$ for the free - free, free - bound, and line radiation, respectively. A fraction of this power will go to each of the thruster surfaces.

In addition to the power deposited into the electrodes and backplate there will be ohmic losses in the electrode current leads. These losses must be minimized without increasing the heat conduction from the electrodes to the low temperature current conductors. Depending on the design, these conduction losses can reach $0.1 \mathrm{MW}$, power which must be removed from the system either by radiation or regenerative cooling.

Regenerative cooling with cold gaseous hydrogen may be beneficial. Assuming that the required $2.5 \mathrm{~g} / \mathrm{s}$ of hydrogen is vaporized at $25 \mathrm{~K}$ near the magnet, and that the hydrogen is in equilibrium with the $1400 \mathrm{~K}$ boron nitride backplate when it enters the thruster, a total of $48 \mathrm{~kW}$ of power is absorbed by the hydrogen. This potential heat sink can absorb all the power from plasma radiation and particle flux, and most likely will be able to cool the electrical conductors attached to the anode and cathode. 


\section{Applied-Field Magnet}

The principal problem with applied-field thruster design is to minimize the power loss in the appliedfield coil without sacrificing the simplicity and robustness that makes MPD thrusters attractive. Thus, while it may be possible to build a superconducting coil with the desired field strengths, the complexity associated with the helium liquefaction system makes this option unattractive. While developments in high-temperature supeconductivity may alleviate this problem, the authors are not aware of a demonstrated high-temperature superconductor that will satisfy the field requirements. The optimal applied-field coil appears to be an aluminum coil kept at $20 \mathrm{~K}$ by a liquid hydrogen bath. The resistivity of aluminum at liquid hydrogen temperatures, $1.2 \times 10^{-9} \mathrm{ohm}-\mathrm{cm}$, is over an order-of-magnitude below that of oxygen-free copper. Several multi-Tesla field magnets have been designed using this concept (Gibson et al. 1990, Cope et al. 1990). For the coil described above the total ohmic power dissipated in the coil would be 60 or 479 $\mathrm{W}$ for the 20 and $40 \mathrm{~cm}$ radius coils, respectively. Using the heat of vaporization of hydrogen, $433 \mathrm{~kJ} / \mathrm{kg}$ at $101 \mathrm{kPa}$, this would vaporize 0.14 or $1.11 \mathrm{~g} / \mathrm{s}$ of hydrogen if the full $0.5 \mathrm{~T}$ field strength were required. This is less than the approximately $2.5 \mathrm{~g} / \mathrm{s}$ hydrogen required for thruster operation, indicating that the mass flow rate might be controlled using a small heat source $(<500 \mathrm{~W})$ to vaporize the needed hydrogen.

In addition to the ohmic losses in the applied-field coil the magnet cooling system must process the heat radiated from the thruster anode and the back surface of the $1.2 \mathrm{~m}$ diameter radiator to the coils (Figure 4). Reducing the emissivity of the anode/heat pipe surface to 0.14 by either polishing or coating the surface yields a heat transfer of $5.2 \mathrm{~kW}$ from the anode and $0.87 \mathrm{~kW}$ from the radiator for the dimensions given above. Radiation shields are thus necessary to reduce this heat flux to a level commensurate with vaporizing the required mass flow rate of liquid hydrogen. The minimum number of radiation shields required was estimated using standard radiation shielding equations from Siegel and Howell (1972). Appropriate emissivities were used for each shield material, which ranged from polished tantalum $(0.11)$ near the anode to polished copper $(0.06)$ near the magnet. Providing for a factor of two margin on the boiloff, and using the $20 \mathrm{~cm}$ diameter magnet, the radiated heat flux to the magnet must be reduced to $480 \mathrm{~W}$, or a factor of 12 below that emitted from the anode. This can be accomplished using ten $0.08 \mathrm{~cm}$ thick heat shields inserted between the anode and magnet and the radiator and magnet. Thermal expansion estimates for the heat shields show that a maximum of sixteen shields may be accommodated in the $5 \mathrm{~cm}$ gap between the anode and magnet, though many more could be accommodated behind the radiator.

A potential problem with using liquid hydrogen vaporization to absorb the heat generated in, and transferred to, the magnet is localized boiling on the magnet coils leading to thermal runaway. The resistivity of aluminum increases rapidly above $25 \mathrm{~K}$, which could potentially result in catastrophic failure of the magnet. While two phase flow of liquid hydrogen is poorly understood, results given by Baker (1985) indicate that the vapor mass flow rate should not exceed between 0.1 and I percent of the total mass flow rate to ensure that the flow remains in a "bubble" mode. While this requirement is not firm, it is clear that the heat leaks to the magnet should be minimized, as even the $0.14 \mathrm{~kW}$ generated by ohmic heating of the $20 \mathrm{~cm}$ radius magnet will cause the gas fraction to exceed $5 \%$. This indicates that the smaller magnet may prove better due to its lower ohmic losses. However, the problem might be solved by forcing a large recirculating flow of liquid hydrogen through the magnet to keep localized boiling from becoming a problem, and providing a mechanism for extracting only the needed propellant from this stream.

\section{Summary}

Performance and lifetime requirements were used to establish a baseline $2.5 \mathrm{MW}$ applied-field MPD thruster designed to operate at a discharge current of $10,000 \mathrm{~A}$, a voltage of $250 \mathrm{~V}$, and a hydrogen propellant flow rate of $2.5 \mathrm{~g} / \mathrm{s}$. The thruster consists of a $15 \mathrm{~cm}$ radius, $30 \mathrm{~cm}$ long, molybdenum anode, and a $2.5 \mathrm{~cm}$ radius, $10 \mathrm{~cm}$ long impregnated tungsten cathode. Lithium heat pipes are used to transport the $\sim 233 \mathrm{~kW}$ of power deposited onto the anode to a $1.2 \mathrm{~m}$ diameter pyrolytic graphite radiator. The appliedfield magnet is made of aluminum conductor cooled to $20 \mathrm{~K}$ using a liquid hydrogen bath. Power dissipated by the coil when generating a $0.5 \mathrm{~T}$ magnetic field is less than 0.02 percent of the thruster power, and the magnet could be kept at a constant temperature by vaporizing a fraction of the required $2.5 \mathrm{~g} / \mathrm{s}$ hydrogen mass flow rate. Chamber wall heat flux estimates based on the plasma characteristics, materials, and geometry show that it should be possible to regeneratively cool all thruster surfaces other than the anode using $25 \mathrm{~K}$ gaseous hydrogen coming out of the magnet. This analysis indicates that the proposed baseline 
design would satisfy the performance and lifetime requirements for multimegawatt nuclear electric propulsion systems.

\section{Acknowledgments}

This work was done at the NASA Lewis Research Center under Contract NAS3-25266.

\section{References}

Auweter-Kurtz, M., et al. (1990) "Cathode Phenomena in Plasma Thrusters," AIAA Paper 90-2662.

Baker, R. (1985) Cryogenic Systems, Oxford Press, NY.

Bohdansky, J., Roth, J., and Bay, H.L. (1980) "An analytical formula and important parameters for lowenergy ion sputtering," L.Appl. Phys., Vol. 51, No. 5., pp. 2861-2865.

Cope, D.B., Snyder, M.D., and Weissman, R.M. (1990) "The Magnetic and Structural Design of a Liquid Hydrogen-Cooled Magnet Utilizing High Purity Aluminum Conductors and a Boron/Epoxy Composite as Structural Reinforcement," in Advances in Cryogenic Engineering, Vol. 35, R.W. Fast, editor, Plenum Press, N.Y., 1990.

Coones, E.P., King, D.Q., Cuta, J.M., and Webb, B.J. (1986) "PEGASUS: A Multi-Megawatt Nuclear Electric Propulsion System," AlAA Paper 86-1583, June 1986.

Curran, F. M., Bennett, G.L., Watkins, M.A., Byers, D.C., Brophy, J.R., and Sercel, J.C. (1991) "An Overview of the NASA Electric Propulsion Program," IEPC 91-002, Presented at the 22nd International Electric Propulsion Conference, Vaireggo, Italy, October 1991.

Dunn, P.D. and Reay, D.A. Heat Pipes, 3rd ed., Pergamon Press, 1982.

Gallimore, A.D., Myers, R.M., Kelly, A.J., and Jahn, R.G. (1991) "Anode Power Deposition in an Applied-Field Segmented Anode MPD Thruster," AlAA Paper 91-2343, June 1991.

Gerwin, R. (1991), "Estimates of Orbit-Raising and Mars Mission Capabilities of Nozzle-Based Coaxial Plasma Thrusters," AIAA Paper 91-3494, Sept. 1991.

Gibson, C.R., Dew, M.W., and Johnson, E.R. (1990) "Design and Analysis of a High-Purity Aluminum Inductor," in Adrances in Cryogenic Engineering, Vol. 35, R.W. Fast, editor, Plenum Press, N.Y., 1990.

Gilland, J.E., Kelly, A.J., and Jahn, R.G. (1987) "MPD Thruster Scaling," AlAA Paper 87-0997, May 1987.

Gilland, J.E., Myers, R.M., and Patterson, M.J. (1990) "Multimegawatt Electric Propulsion System Design Considerations," AIAA 90-2552, July 1990.

Gilland, J.E. (1991) "Nuclear Electric Propulsion Mission Sensitivities," in Magnetoplasmadynamic Thruster Workshop, Proceedings, R. M. Myers, ed., NASA CP 10084, 16 May 1991.

Griem, H. R. (1964) Plasma Spectroscopy, McGraw-Hill Book Co. , 1964.

Hack, K.J., George, J.A., and Dudzinski, L.A. (1991) "Nuclear Electric Propulsion Mission Performance for Fast Piloted Mars Missions," AlAA Paper 91-3488, Sept. 1991.

King, D.Q. and Rudolph, L.K. (1982) "100 kW MPD Thruster System Design," AlAA Paper 82-1897, Nov. 1982.

LaPointe, M.R. (1989) Personal Communication, Sverdrup Technology, NASA Lewis Research Center Group, Brook Park, OH, 44142. 
Lochte-Holtgraven, W. ed. (1968) Blasma Diagnostics, North Holland Publ. Co., Amsterdam, 1968.

Mantenieks, M.A. and Myers, R.M. (1991) "Hollow Cathode MPD Thruster," IEPC 91-076, presented at the 22nd International Electric Propulsion Conference, Viareggio, Italy, October 1991.

Myers, R. M., Suzuki, N., Kelly, A.J. and Jahn, R.G. (1988) "Cathode Phenomena in a Low-Power Magnetoplasmadynamic Thruster," AIAA Paper 88 - 3206, July 1988, see also Journal of Propulsion and Power. Vol. 7, No. 5, Sept.-Oct. 1991, pp. 760-767.

Myers, R.M. (1991) "Applied-Field MPD Thruster Geometry Effects," AIAA Paper 91-2342, June, 1991, see also NASA CR 187163, August, 1991.

Myers, R. M., Mantenieks, M.A., and LaPointe, M.R. (1991a) "MPD Thruster Technology," AlAA Paper 91-3568, Sept. 1991, see also NASA TM 105242, Oct. 1991.

Myers, R. M., Werhle, D., Vernyi, M., Biaglow, J., and Reese, S. (199lb) "A Preliminary Characterization of Applied-Field MPD Thruster Plumes," AIAA Paper 91-2339, June 1991, see also NASA CR 187165, August 1991.

Polk, J.E., Kelly, A.J., Jahn, R.G., Kurtz, H., Auweter-Kurtz, M., and Schrade, H.O. (1990) "Mechanisms of Hot Cathode Erosion in Plasma Thrusters," AlAA Paper 90-2659, July 1990.

Rudolph, L.K and Ogg, G.M. (1985) "Orbit Transfer Using High Power MPD Thrusters," AIAA Paper 851478, July 1985.

Schoenberg, K., Gerwin, R., Barnes, C., Henins, I., Mayo, R., Moses, R., Scarberry, R., and Wurden, G. (1991) "Coaxial Plasma Thrusters for High Specific Impulse Propulsion," AIAA Paper 91-3570, Sept. 1991.

Schroff, A., Palluel, P., and Tonnerre, J.C. (1981 "Life Tests of Impregnated Cathodes," Applications of Surface Science, Vol. 8, pp. 36-49, North Holland Publ. Company, 1981.

Siegel, R. and Howell, D. (1972) Thermal Radiation Heat Transfer, McGraw-Hill, N.Y., 1972.

Sovey, J. S. and Mantenieks, M.A. (1988) "Performance and Lifetime Assessment of MPD Arc Thruster Technology," AIAA Paper 88-3211, July 1988, see also Joumal of Propulsion and Power. Vol. 7, No. I, Jan-Feb 1991, pp. $71-83$.

Sovey, J. S., Vetrone, R.H., Grisnik, S.P., Myers, R.M., and Parkes, J.E. (1991) "Test Facilities for High Power Electric Propulsion," AIAA 91-3499, Sept. 1991.

Wegmann, T., Auweter-Kurtz, M., Kurtz, H., Merke, W., Loesener, O., and Schrade, H.O. (1990) "Steady State High Power MPD Thrusters," AIAA Paper 90-2555, July 1990. 


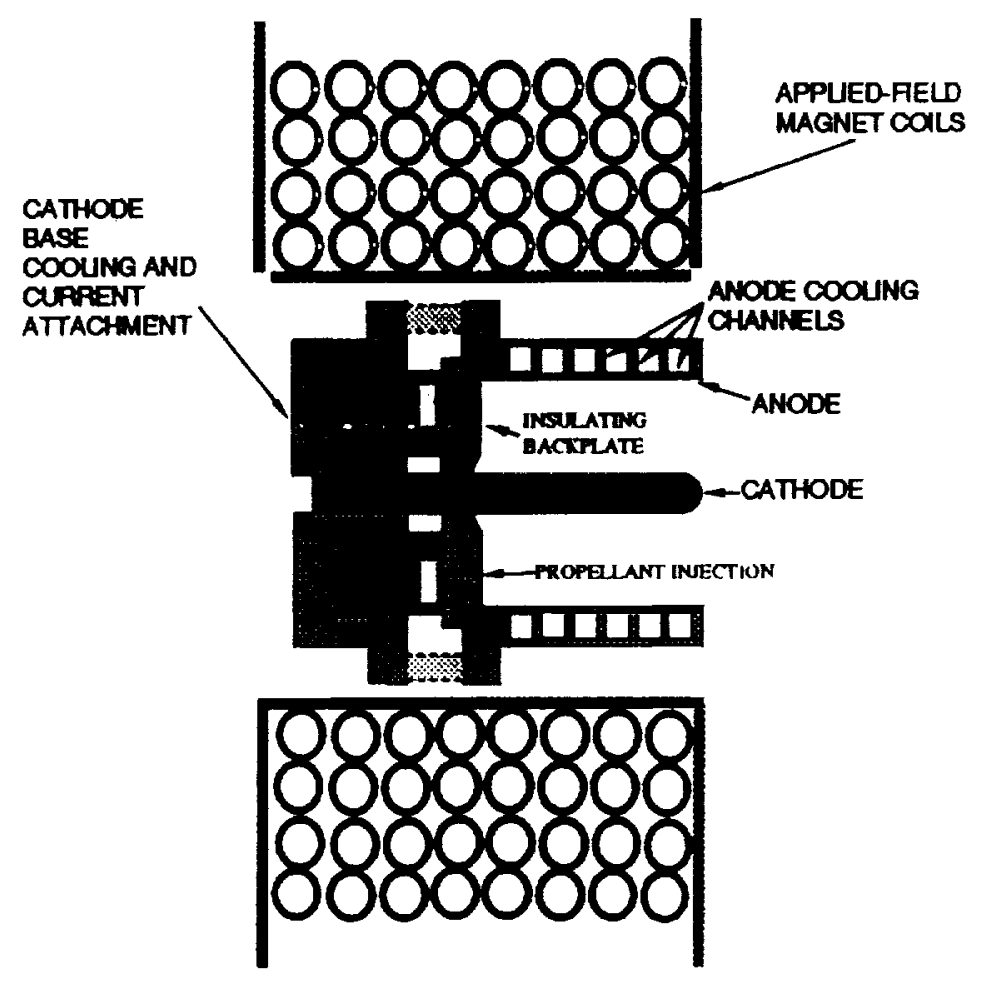

FIGURE 1 - Schematic of water-cooled laboratory MPD thrusters.

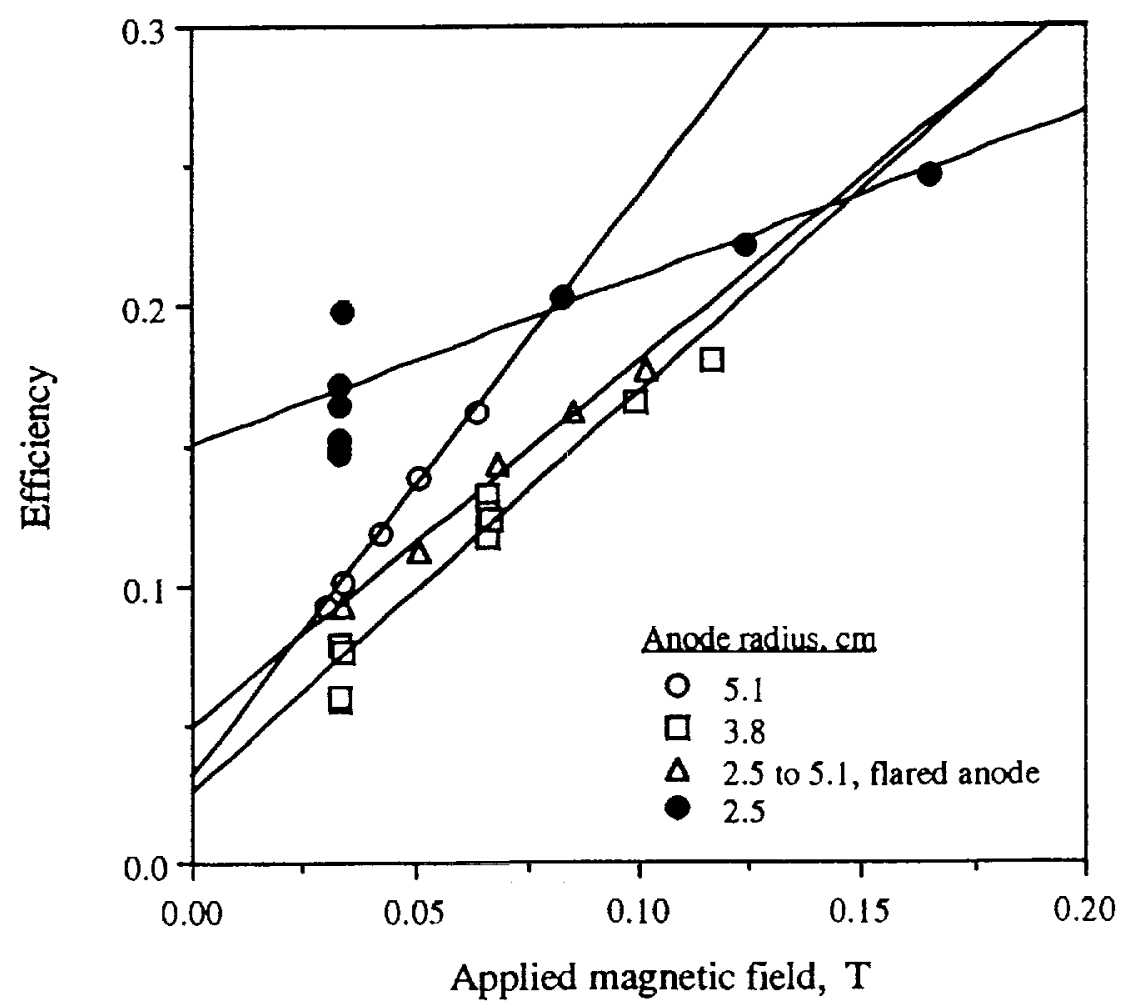

FIGURE 2 - Efficiency versus Applied-Field Strength for Four Anode Radii Operated on $0.1 \mathrm{~g} / \mathrm{s}$ Argon Propellant. Bischarge Current was $1000 \AA$, Anode Length was $7.6 \mathrm{~cm}$ (Myers 1991) 


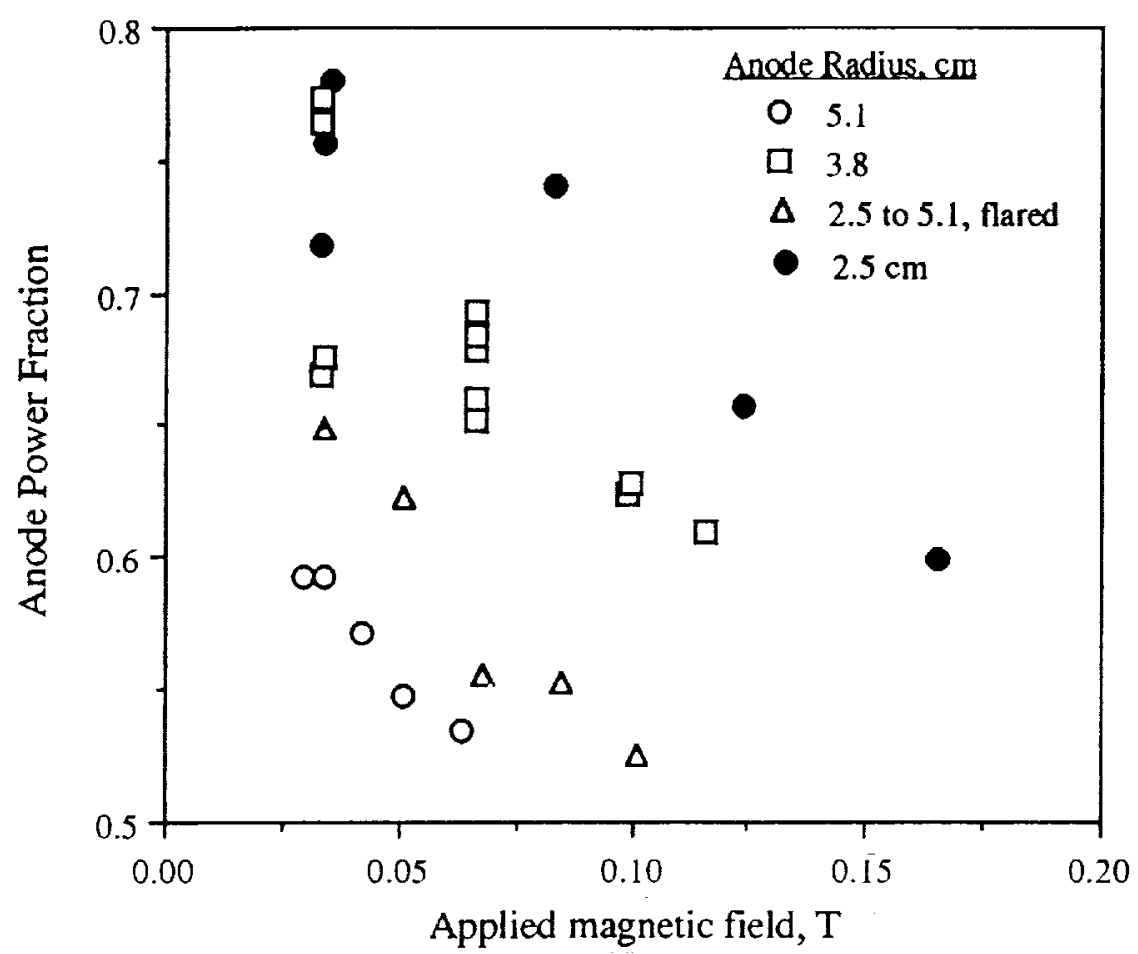

FIGURE 3 - Anode Power Fraction versus Applied Magnetic Field Strength for Four Anode Radii Operating on $0.1 \mathrm{~g} / \mathrm{s}$ Argon Propellant. Discharge Current was $1000 \mathrm{~A}$, Anode Length was $7.6 \mathrm{~cm}$ (Myers 1991 ).

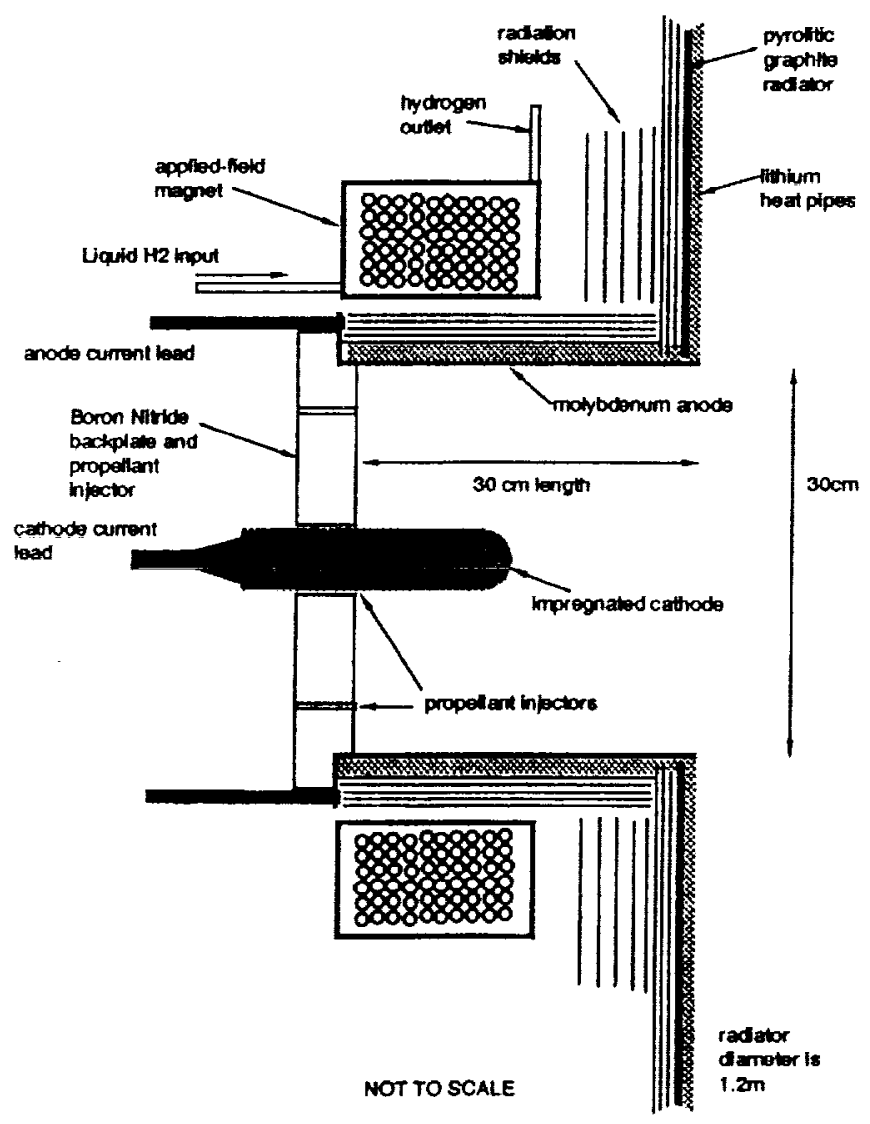

FIGURE 4 - Proposed 2.5 MW MPD Thruster Design. 


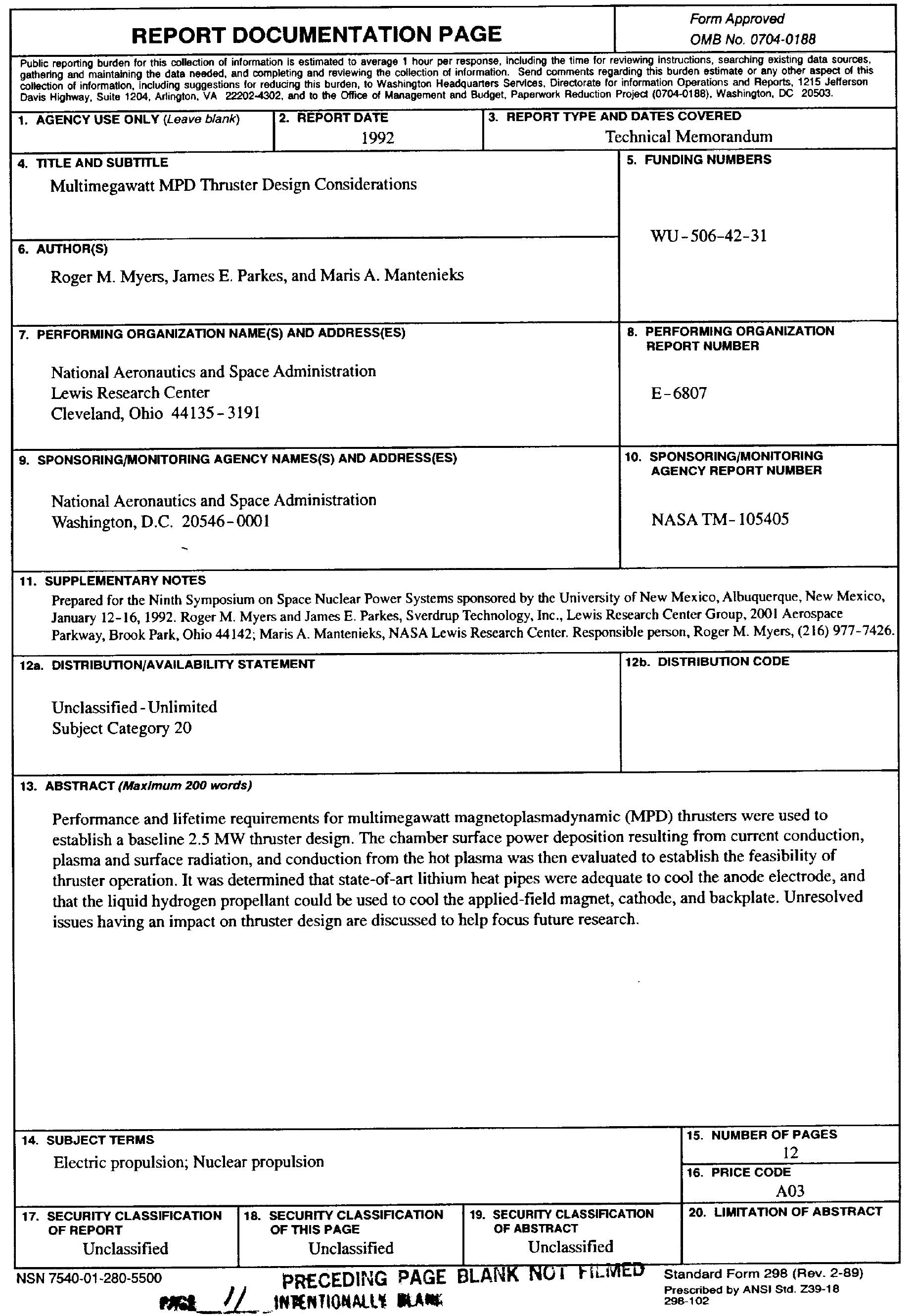


